\title{
GUIDED TOUR: in the ways of half a century of history of the first hotel-school of latin américa
}

\author{
Leila de Assis Cobuci a; \\ Thaís Oliveira Da Dalt b; \\ Nathália Mendes do Amaral c
}

ABStRACT: This work is the result of experiences lived during the stages of the project "Interpreting the ways of the HotelSchool Senac Grogotó: thematic routes as tools to promote the appreciation of the history and heritage preservation in Senac unit in Barbacena-MG." The project was developed under the extension program of the Technology School of Senac Minas, together with the graduation courses of technology in hospitality and gastronomy. The project is characterized by offering thematic routes, structured as a guided tour, which are conducted by students of the institution in order to present the history and the heritage of the hotel, aiming to sensitize students, guests and other social groups in the community. The development of research and data collection took place between July 2016 and July 2017, and currently the project is still active, with the visits already implemented, as will be seen in the topic Methodology. The methodology used was the exploratory research and intervention research. For this, information was collected from various sources of research that enabled the formatting of a tour script, which was categorized and sectorized. Within this context, it was aimed through the formatting of the guided tour the consolidation of guidelines and methodologies for the reception of groups. This initiative intended to professionalize and expand the visitation to the complex of Hotel School Grogotó. The consolidation project in Barbacena Senac unit is an effective strategy to publicize the heritage and also the educational expertise of the institution, especially in the theme of hospitality. As a result, it provided the recognition and revaluation of historical and cultural aspects of the $1^{\text {st }}$ Hotel-School in Latin America, offering to Barbacena community and other interested parties educational and entertainment opportunities. The guided tour is formatted in seven points of interpretation, and along the route the places of the Hotel-School that present as relevant spaces in the professional technical training since the year 1960 are visited. In this sense, the project contributes to creating places for students and teachers to experience and materialize the

\section{KEYWORDS}

Heritage

History

Guide tour

Hotel school 


\section{INTRODUCTION}

The objective of this project is to strategically explore the history and heritage of the first Hotel-School of Latin America, in order to format a product based on theoretical and methodological guidelines for the structuring of interpretative itineraries related to the historical and cultural heritage. Thus, it is highlighted the offering of interpretative tours in the complex of Hotel School Senac Grogotó as cultural heritage of the city of Barbacena, aiming to sensitize students, guests and the local community for the recognition and perception of this environment, establishing emotional ties and transforming this space into an identity of the city.

The Hotel-School Senac Grogotó is part of the complex of the Faculty of Technology Senac Minas in Barbacena-MG, therefore, it is part of the institution to which the extension project is linked. Thus, with the physical proximity and easy access to the premises, documents and history of the place, the object of study was chosen. The Hotel is an element of historical relevance for tourism, not only in Minas Gerais, but also for the country. In this way, the historical aspect was added to the choice of the object.

It should be noted that the history of the HotelSchool Senac Grogotó began in the 1950s, along with the preservation measures of the colonial cities of MG. Such measures, supported by former governor Juscelino Kubitschek, sought to move tourism from the so called "cities of the waters", such as Caxambú, Lambari and São Lourenço. In order to achieve this objective, the extinct Hidrominas autarchy was created, which had as one of its functions, to stimulate and regulate tourism to the cities of the waters. To reach these cities, Barbacena acted as a geographic link, since it is located between large capitals, such as Rio de Janeiro and Belo Horizonte. Thanks to the implementation of this tourist program, there was an increase in the flow of tourists in MG. Thus, with the need to create the necessary infrastructure, the construction of tourist installments began, through Hidrominas, such as the Hotel-School Senac Grogotó, which later became a property of Senac
Minas.

This Hotel started its activities as a Hotel-School in 1968, and since then it has always offered several courses in the hospitality area. In addition to this educational bias, the Hotel has built its brand as a heritage of the city of Barbacena over the years. Today, the Hotel-Escola is recognized as a municipal heritage, registered by the local council.

Thus, in this scenario of more than half a century of performance in tourist accommodation and its infrastructure for the education of hospitality, the project 'Guided visit: along the paths of half a century of history of the first hotel-school in Latin America' was structured, as described in this article.

Tourism presents itself as an essential element for the development and maintenance of the hotel activity and depends on strategies that motivate visitation and permanence in destinations.

The guided tour at the hotel is an effective strategy to disseminate and enhance the historical heritage and also the educational expertise of the institution, offering visitors a differentiated and enriching experience. In this context, the appreciation of the material and immaterial heritage of the Hotel-School a Senac Grogotó is highlighted as a form of entertainment for guests and tourists, as well as an opportunity for the external and internal community to better understand the heritage and history of the hotel, thus boosting the practice of tourist activity in the city and region. In a broader perspective, the Hotel-Escola Senac Grogotó has potential as an attractive and cultural heritage of the city, especially for its historical heritage, which contributes to the visitors' interest in knowing its history. The article is divided into five sections. It brings this first introduction, which presents the object of study and objectives of the work. In the second section we discuss the characterization and relevance of the project. The third section describes the methodology used. The fourth section deals with the analysis of the results, such as the nature of the experience, the target audience and the main design features. Finally, we point out the practical implications, the impacts of this experience and the conclusions.

\section{Problem and Relevance}


Regarding the situation to be presented in the case of this extension project, it is understood that there is no specific problem to be solved. What exists is a social context with which one intends to interact, meeting social needs and promoting the exchange between the College Senac Minas and the society of Barbacena, a social reality with which this project dialogues. This experiment aims to answer the need to approach of this space with the community, and the improvement and professional development of students. Thus it provides opportunities to students to interpret the heritage, plan products and tourism services, structure thematic tours and experience the practice as monitors of the guided tours in the created itineraries.

It is considered that the social intervention perspective does not exclude the necessity and importance of the academic context of the project which, in this case, encompasses the theoretical and methodological debate on heritage interpretation and thematic itineraries, and also contemplates the historical and patrimonial importance of the Hotel-School Senac Grogotó and the entire Senac Minas unit in Barbacena.

\section{METHODOLOGICAL ASPECTS}

For this project it was conceived a permanent procedure, which was developed in three stages: I- bibliographic and documentary research, empirical data collection II- and III- deployment of the guided tour. The preparation and monitoring of the planning stages was systematized so that the performance of activities would reach the expectations of the participants and, consequently, guarantee the success in the proposal.

The first stage included the exploratory research covering the literature on the topics that underlie the development of the project, which includes, among others, historical heritage, heritage interpretation and interpretative tours. In this first stage, it was possible to systematize the references about the history and heritage of the Hotel-School Senac Grogotó located in Barbacena, Minas Gerais. In addition, it was sought in collections and archives documents and records that enabled this survey about the historical and heritage of the Hotel.
The concept of historical heritage is linked to the enjoyment of a patrimony by a community, constituted by the continuous accumulation of a variety of objects that come together by their common past: works and masterpieces of "fine arts and applied arts, jobs and products all the knowledge and savoir-faire of human beings (Chaoy, 2011, p.11)".

The second stage involved the collection of empirical data. At this point, it was defined the sampling of individuals who would be surveyed, which included employees, former employees and patrons of the Hotel and research unit. Thus, it was structured questionnaire to collect data and information. Finally, questionnaires were applied to the established to the sampling groups and data was subsequently analyzed and tabulated. A theoretical-methodological reflection for the structuring of the visitation was provoked, with emphasis in the oral history and field immersions.

According to Amado and Ferreira (2006, cited by Coutinho et al., 2017, p.104) "it is important to note that oral history, empirical field studies and theoretical and methodological reflection are inextricably linked, and that the historical object is always result of a elaboration and construction."

In this study, we highlight as a methodological approach the intervention research. According to the authors Passos and Benevides Barros (2000) this is a form of research that takes an ever-interventionist character of knowledge, for in any of its moments all knowledge is a do "In intervention research, as we understand it, it is its scale of production that compromise, initially, the subject-object dichotomy. In the same direction, another dualism is shaken when it is affirmed the character of the creation of the intervention, as the theory and practice of notions are necessarily reequationed. Traditionally, the theoretical moment of knowledge refers to the logical construction of a system of intelligibility for the object, and the technical moment says about the practical intervention on the object (Passos \& Benevides de Barros, 2000 p.73)".

The third methodology stage of the project included the implementation of the thematic itineraries through the guided tour. From the techniques and 
methodologies structured in the first stage and the analysis of data collected in the second stage, the itineraries were delineated, mapped and defined. At this stage, field activities at the Hotel were needed for physical recognition and characterization of the heritage that would later be points of interpretation. Firstly, the routes of the itineraries were defined, then the interpretative elements, so the interpretation points were identified and structured.

In this sense, it is emphasized that the interpretative itineraries can promote the recovery of the local culture, valuing the elements linked to the process of belonging, especially for exposing the culture, traditions, gastronomy, identity, and other cultural elements. The patrimonial interpretation methodology becomes relevant, because it can be understood as the presentation of the patrimony which employs a set of communication techniques, providing the interaction between the cultural heritage and the society (Morales, 2004).

After the processes mentioned above techniques and types of interpretation for the guided tour were selected, which enabled the implementation of the thematic itineraries. Finally, the execution of the guided tour pilot experience allowed the improvement of the product to offer to the public. This activity generated an assessment of the strengths and weaknesses of the project, promoting a review of the conduction dynamics for the visitors. Thus, it can be seen in Table 1 a summary of the final format of the tour, namely seven points of interpretation. It is important to note that at each point along the route and relevant sites for the interpretation routes, interpretative panels are posted on the walls and next to works of art. These panels serve as points of information and complement the lines of the guides leading the visit. In the panels are found old and recent photos, as well as relevant historical data.

\section{Table 1: Interpretation points}

\begin{tabular}{l|l|l}
\hline \multicolumn{3}{c}{ Interpretation points } \\
\hline 1 & $\begin{array}{l}\text { This point is located at the hotel } \\
\text { entrance, contextualizing the po- } \\
\text { The door- } \\
\text { way to the } \\
\text { story }\end{array}$ & $\begin{array}{l}\text { litical and historical aspects that } \\
\text { permeated the time of its con- } \\
\text { struction. }\end{array}$ \\
\hline
\end{tabular}

\begin{tabular}{|c|c|c|}
\hline 2 & $\begin{array}{l}\text { The con- } \\
\text { struction of } \\
\text { a reference } \\
\text { in education } \\
\text { and the } \\
\text { social im- } \\
\text { portance of } \\
\text { this story }\end{array}$ & $\begin{array}{l}\text { This point is located in noble hall } \\
\text { of the Hotel (space located near } \\
\text { the reception). At this point it is } \\
\text { highlighted the pioneering imple- } \\
\text { mentation of a structure, with in- } \\
\text { novative pedagogical proposals for } \\
\text { professional education, which be- } \\
\text { came the first hotel-school in Latin }\end{array}$ \\
\hline 3 & $\begin{array}{l}\text { The art } \\
\text { collection }\end{array}$ & $\begin{array}{l}\text { The art collection is found on vari- } \\
\text { ous spaces of the hotel, such as } \\
\text { the reception, auditorium, games } \\
\text { room and hallways. At this point } \\
\text { we present the arts collections and } \\
\text { antiques, the author and date of } \\
\text { each work. }\end{array}$ \\
\hline 4 & $\begin{array}{l}\text { The flavors } \\
\text { of success }\end{array}$ & $\begin{array}{l}\text { This point is located in the hall } \\
\text { between the Scotch Bar and Res- } \\
\text { taurant. At this point, the visitor } \\
\text { will know some of the stories that } \\
\text { made the hotel a reference in- } \\
\text { school vocational education in } \\
\text { gastronomy. }\end{array}$ \\
\hline 5 & $\begin{array}{l}\text { Guests who } \\
\text { made histo- } \\
\text { ry }\end{array}$ & $\begin{array}{l}\text { To this point, the housing unit is } \\
\text { visited and stories of guests that } \\
\text { have marked the history of the } \\
\text { hotel are told. }\end{array}$ \\
\hline 6 & $\begin{array}{l}\text { Celebrities } \\
\text { and their } \\
\text { visits to } \\
\text { Grogotó }\end{array}$ & $\begin{array}{l}\text { At this point, which is situated in } \\
\text { the outer area, it is approached } \\
\text { through the interpretative panels } \\
\text { the evolution and transformation } \\
\text { of the hotel spaces throughout } \\
\text { history. In this environment, it is } \\
\text { also exposed curiosities of person- } \\
\text { alities who have attended and / or } \\
\text { are regulars on the hotel. }\end{array}$ \\
\hline 7 & $\begin{array}{l}\text { The taste of } \\
\text { the unfor- } \\
\text { gettable } \\
\text { sunset }\end{array}$ & $\begin{array}{l}\text { This point is located within the } \\
\text { Scotch Bar, to visualize the sunset } \\
\text { (this time is subject to the time } \\
\text { that the visit occurs). }\end{array}$ \\
\hline
\end{tabular}

Source: Adapted from Coutinho et al. (2017)

In this perspective, it is presented the story of half a century of the hotel, through the guided tour of the exhibition held by student monitors leading groups through the interpretative points, explaining the history and heritage importance of the Hotel-School Senac Grogotó. 


\section{RESULTS}

The tour described above was implemented in the Hotel School Senac Grogotó, Barbacena, Minas Gerais. The target audience reached with the project were students and staff, the academic community Barbacena and tourists and visitors of the Hotel School Senac Grogotó. Thus, as we will see next, the experience has characteristics such as reproducibility, low cost, interdisciplinarity and provides memorable experiences.

Regarding replicability, this project is entirely possible, considering that its format followed a consolidated theoretical basis that enables the structuring with methodological bases and guidelines that can be replicated in similar scripts. Visiting itineraries are justified by new opportunities for tourist activity. For a script to be developed it must be based on something representative, such as culture, local identity or heritage.

According to the Ministry of Tourism (2010, p.31) "The routing process is therefore a way of ordering a set of specific thematic tourist attractions for promotion and marketing in the market, making it adistinct tourist option". In this context, it is understood that with the basic and methodological application already consolidated in this project, one can adapt to local specificities and repeat the experience in other contexts.

In addition to replicability, it is noteworthy that the proposal is presented in this project implies the execution in a low total cost. For the execution of the project few resources were used, considering the financial resources were used initially for the production of information boards and payment of scholarships for two participating students: the other monitor students work voluntarily. Thus, the project needs little investment.

Promotion and advertising can be done through actions already established in the planning of the organization.

In addition to the low costs involved in the development, the creation and consolidation of new itineraries make it possible to increase visitation rates, stay rates and average tourist spending at destinations, resulting in the immediate creation and expansion of jobs and, therefore, as a consequence of the medium and long term, the promotion of social inclusion, a better income distribution and the reduction of regional and social inequalities (Ministry of Tourism, 2010).

Besides the economic characteristics, it is worth pointing out the relevance of this project to hospitality and gastronomy professionals as a tool to qualify learning and to provide in practice the application of knowledge acquired in the classroom. Thus, the interdisciplinarity of the project addresses issues related to curriculum content and interdisciplinary practices of the course that supports it. It involves the students in a way to corroborate with their integrated learning, in the exercise of exchange of experiences, curriculum improvement, interdisciplinary practices, and in the execution of socially relevant research and projects aimed at meeting the demands of the community.

This project has its execution inside a hotel with more than 50 years of history, which is enough to provide memorable experiences for visitors. Thus, the project offers tourists and visitors of the Hotel School Senac Grogoto the opportunity to make guided tours and learn more about the enterprise and the institution. The itineraries can be configured for the client as with more than one entertainment option. This entertainment can in turn add value to guest experiences and positively impact guest satisfaction. The interpretative itineraries promote the rescue of the culture of the place, valuing the elements linked to the process of belonging, mainly by showing the culture, traditions, gastronomy, identity, and other cultural elements.

An itinerary can represent an identity and memory value. Visiting itineraries are justified by new opportunities for tourist activity. For an itinerary to be developed it must be based on something representative, such as culture, local identity or heritage. "Tourist itinerary is an itinerary characterized by one or more elements that give it identity, defined and structured for the purposes of planning, management, promotion and commercialization of tourism (Ministry of Tourism, 2010, p.52)". An itinerary is not only an indication of a tour, it must be aware of rules, information and so that its operation helps achieve what they propose.

In other words, the script is a route with historical context that carries cultural and heritage identification, and the Hotel School Senac Grogotó is recognized for its excellence in gastronomy, being one of the cultural 
pillars that are addressed during the tour. Therefore, these activities provide memorable experiences for tourists, visitors and guests of the Hotel School.

\section{FINAL CONSIDERATIONS}

From the perspective of the impact that experience produces it is expected that this project will contribute to the transformation of the local community through learning, albeit indirectly, collaborate for greater visibility of the Senac Minas College - Barbacena unit in society, fostering institutional culture in relation to the extensive practices.

The relevance of the project is due to its versatility with regard to the articulation with teaching and the research. The joint project with the teaching takes place in that it seeks to equate, in the didactic-curricular framework, the technical specifications with the requirements of citizenship education. The link to the survey is guided in the questioning of the relevance of social studies on interpretation, appreciation, and historical heritage education characterized as crosscutting themes of hospitality and cuisine, and applied social sciences.

The social relevance of the project should also be pointed, justified by the potential of the thematic itineraries and their respective interpretative activities regarding the promotion of education and heritage awareness, as corroborated by Cardozo (2007) "more than inform, the interpretation aims to raise awareness of the tangible and intangible heritage, this awareness is not just for tourists but for the whole community (Cardozo, 2007 cited Pucci; Cardozo, 2008, p. 6)".

The project offers educational opportunities of educational nature, with the execution of socially relevant actions that seek to meet the demands of the internal and external community, in addition to all the other aspects that have already been addressed throughout this paper, such as society-school integration, knowledge exchange, professional development opportunities for students and teachers, and the generation of memorable experiences for all participants in the process.

\section{REFERENCES}

Brazil. (2010). Ministry of Tourism Segmentation of tourism and the market. Brasilia: Ministry of Tourism.

Chaoay, F. (2011).The allegory of the equity. St. Paul: Liberty Station, Publisher Unesp.

Coutinho, Z.,\& Matos et al.(2017). Interpreting Grogotó paths. In the Mining Journal Beginnings Kitchen: History at the table. Belo Horizonte: Senac. v, 5, n.1, pp.98-117.

Steps, E., \& Barros B.R. (2000). Construction of the clinical plan and the concept of transdisciplinarity. Psychology: Theory and Research. v. 16, no. 1, p. 71-79.

Pucci, P. R., Bannach.,\& Cardozo, P.F.(2008). interpretive planning of historical and architectural cultural heritage of the central city of Castro-PR. Tourism and Society, vol. 1, no. 2,

Morales, J. (2004). La interpretación en su acepción de comunicación attractive situ. Cultural Bulletin Gestión, v. 8,

Murta, S. M., \& Goodey, B. (1995). Heritage interpretation for Sustainable Tourism - A Guide. Belo Horizonte: SEBRAE (MG).

\section{ATTACHMENTS}

\section{Interpretative Panels}
INTERPRETANDO OS CAMINHOS DO HOTEL SENAC GROGOTÓ

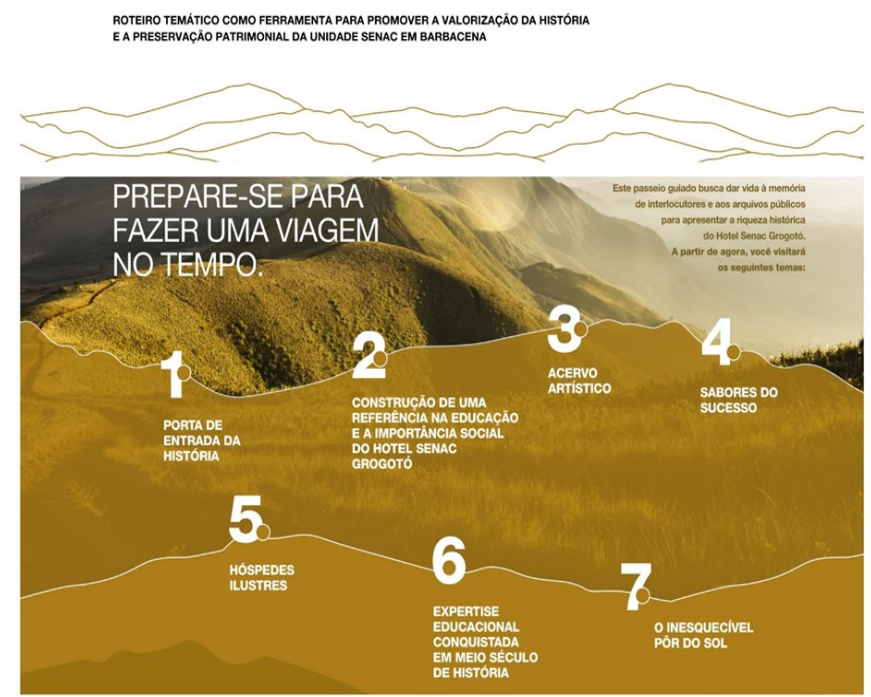



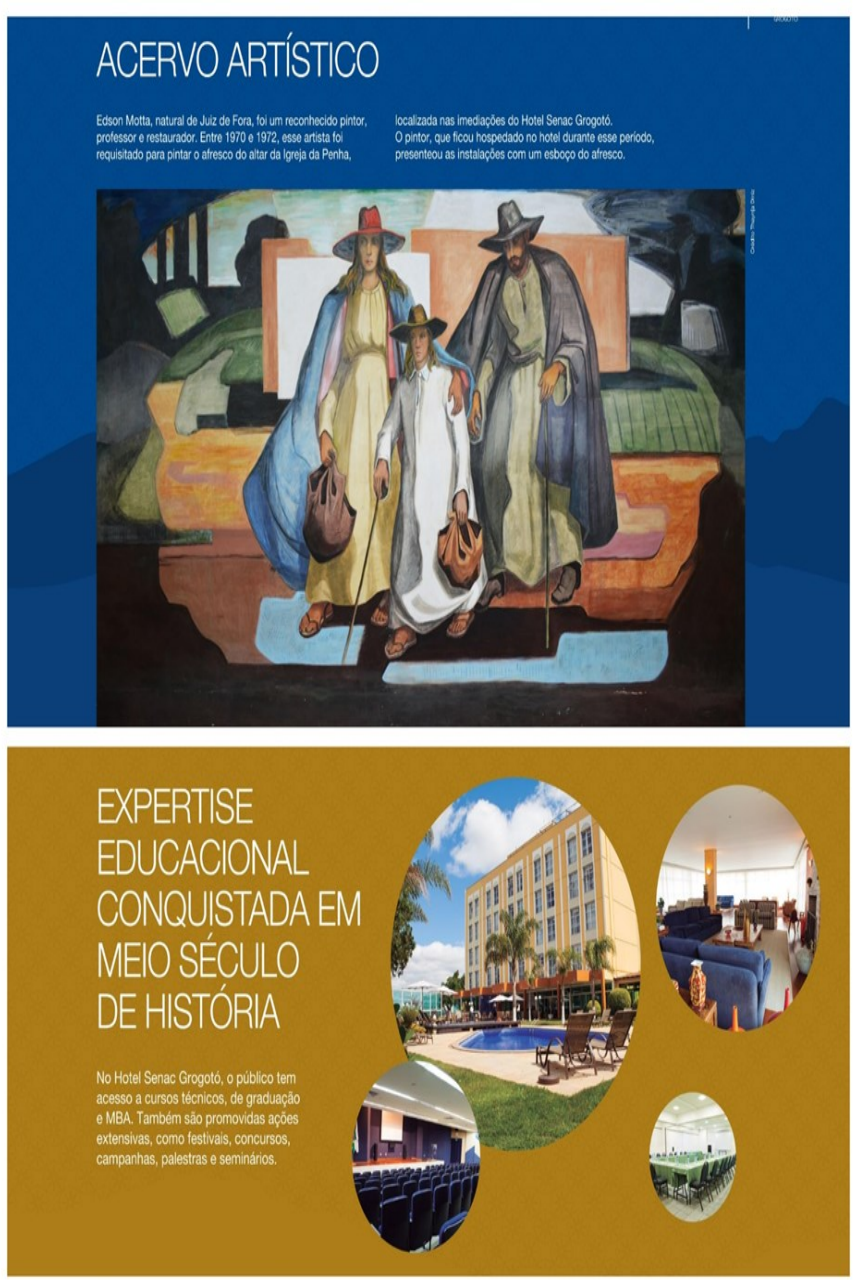